\title{
O Uso da Semiótica para Pesquisas em Turismo
}

Rodrigo Guissonia

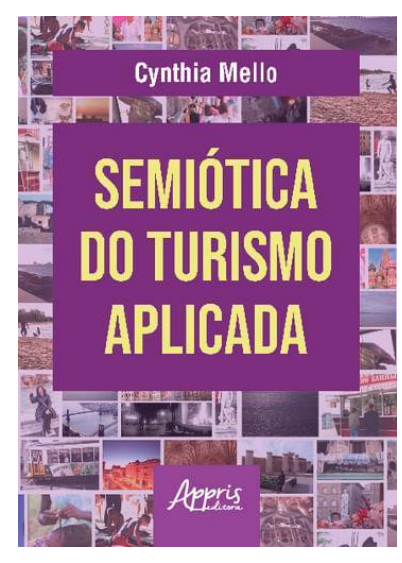

\section{Resumo}

Resenha do livro Mello, C. (2019). Semiótica do turismo aplicada. Curitiba, PR: Appris. Palavras-chave: Metodologia; Processo de significação; Discursos; Fotografia.

\section{Abstract}

\section{The use of semiotics for tourism research}

Book review Mello, C. (2019). Semiótica do turismo aplicada. Curitiba, PR: Appris.

Keywords: Methodology; Signification process; Discourses; Photography.

\section{Resumen}

El uso de la semiótica para la investigación turística

Reseña de libro Mello, C. (2019). Semiótica do turismo aplicada. Curitiba, PR: Appris.

Palabras clave: Metodología; Proceso de significación; Discursos; Fotografía.

\section{INTRODUÇÃo}

Todos somos cientes de que o turismo é composto por elementos visuais. Nesse sentido, para além da viagem enquanto desejo até sua efetivação, busca-se primeiro a satisfação visual no belo, no interessante ou no diferente, visto como exótico, e só então os demais sentidos permitirão a ampliação da experiência sinestésica ao lugar. Essa busca pelo que é diferente, fora da rotina habitual, se confirma por meio dos discursos verbo-visuais do turismo.

a. Doutorando em Geografia pela Universidade Federal do Paraná (UFPR). Curitiba, Paraná, Brasil. E-mail: guissonirodrigo@gmail.com 
Desse modo, o livro Semiótica do Turismo Aplicada emerge como uma possibilidade para se trabalhar esses discursos verbo-visuais através de teorias e métodos semióticos, didáticos, diretos e específicos ao universo turístico. Apresentado como resultado da pesquisa de pós-doutorado realizada por Cynthia Mello (2019), este livro é o primeiro do gênero no Brasil a aplicar a temática da semiótica aos estudos visuais turísticos.

A autora também trouxe para o contexto exemplos populares, figuras, trechos, citações, autores e obras densas do estudo da semiótica de maneira lúdica. Esses aportes teóricos se mostraram facilitadores àqueles que nunca tiveram contato com o universo da semiótica.

A autora Cynthia Mello desponta como a principal estudiosa em semiótica do turismo no Brasil. Ela possui dois pós-doutorados, pela Universidade Federal do Paraná (UFPR) e pela Escola de Artes, Ciências e Humanidades da Universidade de São Paulo (EACH-USP); é doutora em Comunicação e Semiótica pela Pontifícia Católica de São Paulo (PUC-SP); mestra em Ciências da Comunicação pela Escola de Comunicação e Artes da Universidade de São Paulo (ECA-USP); e especialista em Teoria da Comunicação pela Faculdade Cásper Líbero.

Além disso, atuou como colunista no jornal $O$ Estado de S. Paulo; foi professora de ensino superior; presta consultoria e lidera o Grupo de Estudos em Semiótica do Turismo (GEST); possui vários artigos publicados nessa e em outras temáticas como visualidades, imaginários e fotografias turísticas, o que denota notório saber e autoridade à finalidade que se destina sua obra.

Assim como em seus artigos, a autora retoma, no livro, a temática das visualidades no universo turístico por meio da fotografia e o comportamento dos produtores e consumidores de conteúdo visual turístico, decodificando conceitos, teorias e técnicas da semiótica para mais perto do campo do turismo, para o qual sua contribuição é assertiva. A autora também apresenta a possibilidade de pessoas que não são semioticistas aplicarem técnicas de semiose, ou seja, trata-se de uma estratégia metodológica para que leigos possam recorrer a métodos e técnicas semióticas, ainda que sejam distantes da teoria da significação (Greimas, 1973) ou da doutrina dos signos (Peirce, 1997).

Mello (2019) enfatiza que qualquer pessoa pode alcançar o sucesso metodológico ao analisar contextos verbais e visuais do turismo a partir da semiótica. Nas palavras da autora, essa obra tem como proposta "recomendar instrumentos e quadros conceituais não-homogêneos para análises úteis para muitos pesquisadores" (p. 69), ou seja, um modelo esquemático semiótico flexível e adaptável aos diferentes segmentos turísticos. 0 livro é didático, ilustrado e de fácil assimilação. Tem 221 páginas divididas em quatro capítulos mais a bibliografia.

\section{RESUMO DA OBRA}

No prefácio, o professor doutor Alexandre Panosso Netto, também responsável pela supervisão da pesquisa, ressaltou que o resultado vai além da teoria meramente estratégica de marketing e que a autora apresentou uma proposta pragmática para se pensar/trabalhar a semiótica do turismo através de elementos verbo-visuais presentes em diferentes categorias de comunicação turística. 
Na apresentação, a autora indicou a semiótica do turismo como uma semiótica especial, pois, antes de ser um fenômeno econômico, o turismo é comunicação, produção de sentidos e experiência. A autora se ancorou no imaginário de um sujeito condicionado por signos, símbolos, sinais, objetos e buscou, mediante métodos próprios, acessar e interpretar a comunicação entre enunciadores e enunciatários com o propósito de aprimorar a experiência final.

No primeiro capítulo, "Preparativos à viagem investigativa", a autora sintetiza, de forma objetiva e essencial, o compêndio de autores, correntes e escolas em conjunto com os direcionamentos propostos de maneira assertiva perante o vasto universo semiótico de possibilidades. Essa introdução se mostrou fundamental ao leitor/pesquisador que inicia seus estudos em semiótica.

Na teoria, perpassou a história, os principais termos e conceitos, as escolas, correntes ou linhas semióticas, como o formalismo russo ou semiótica da cultura (Lotman \& Ouspensky, 1976), focado na linguagem contextual de fenômenos; a Teoria da Significação (Greimas, 1973), que se centra no processo de significação; e a Doutrina dos Signos (Peirce, 1997), voltada para o estabelecimento das relações entre os signos. Além disso, abordou as possibilidades e "flexibilidades" que a temática permite.

Na sequência, o capítulo 2, "Impressões de chegada: a semiótica do turismo", adentrou na seara turística com autores, obstáculos, tendências e a proposta da semiótica como uma estratégia metodológica em estudos turísticos, deixando claro que a obra não inaugurou a semiótica do turismo, mas que há a necessidade metodológica constante de aprimoramento científico.

No terceiro capítulo, "Da pragmática da semiótica do turismo", foram feitas apresentações teóricas do universo turístico, com destaque para perspectivas pragmáticas e "não-homogêneas" ao se buscar a interpretação de signos do turismo, marcadores sígnicos, categorias de discursos verbais e visuais. Por fim, o capítulo 4, "Do grande discurso sincrético da viagem perfeita", encerrou o ciclo visual ao superlativar as qualidades do destino através de análises sensoriais.

\section{ANÁlise e AVALIAÇÃo do CONTEÚdo}

Quando se trata de estabelecer vínculos entre semiótica e turismo, o francês Jean-Didier Urbain (1989) trouxe para o meio científico suas análises a respeito do comportamento dos turistas e seus registros fotográficos na forma de consciências narrativas, almejando com finalidades antropológicas o imaginário turístico por meio da disciplina da semiótica narrativa, moderado pela estrutura heurística. Para esse autor, "a publicidade turística é analisada como a memória e o reflexo da consciência narrativa de um viajante" (Urbain, 1989, p. 106, tradução nossa).

Jonathan Culler (1990), outro pesquisador internacional que segue semelhante temática, afirma que todos somos turistas em algum momento de nossas vidas, mas enquanto pesquisadores, o turismo tem poucos defensores e, por isso, torna-se negligenciado. Nesse sentido, em seu estudo The Semiotic of Tourism, o autor utilizou da semiótica no contexto das experiências turísticas culturais, nostálgicas, artificiais e/ou fantasiosas e, assim como na proposta de Mello (2019), defende que é por meio do visual que se consome, planeja e se estabelece um vínculo primário com o destino. 
No que lhe concerne, Echtner (1999) afirmou, em seu estudo ontológico The semiotic Paradigm: Implications for Tourism Research, que a semiótica utilizada em pesquisas visuais turísticas é comumente direcionada a fins econômicos da publicidade e do marketing. Mas seguir somente nesse sentido é negligenciar a totalidade do que a semiótica tem a oferecer às pesquisas turísticas, e até mesmo Echtner (1999) confirma a existência de lacunas quando a semiótica é utilizada apenas para fins econômicos, e menciona a importância de se desenvolver pesquisas semióticas que tenham no turismo seu objeto de estudo.

No meio-termo entre a experiência e a comunicação, Rickly-Boyd (2009) apresentou uma ponte espaço-temporal, ou episódios de uma narrativa pessoal dos momentos turísticos, que age simultaneamente de modo social e semiótico, ou seja, enquanto a obra de Culler (1990) se apresenta como o período equivalente à viagem, à ação experiencial, a obra de Mello (2019) tem como pós-viagem o registro da experiência vivida, em que de um lado se encontra um material de consulta para pesquisadores e, de outro, as narrativas e comprovações de viagens capazes de (re)conectar memórias e (re)produzir significados.

Internacionalmente, Jaworski \& Thurlow (2010) são os que mais se aproximam da proposta de Mello (2019), visto que estabeleceram um diálogo entre a semiótica e a paisagem. Assim, tendo como teoria basilar os geógrafos que discutem os conceitos de paisagem, cultura e espaço, acabaram por perpassar o campo das viagens.

Já na América Latina, Jurado (2002) se apropriou da semiótica como ferramenta para interpretação de objetos (souvenires), enquanto Santillán (2011) se pautou nas visualidades turísticas com direcionamento ao propósito de comercialização de destinos.

Para Jurado (2002), o objeto da viagem (souvenir) é interpretado como "valor-preço" e, assim, coloca o turista como um "observador semiótico", pois quando "um objeto pertence a uma cultura desaparecida ou a algum lugar distante, ele adquire um maior valor econômico" (p. 12, tradução nossa), ou seja, enquanto alguns pesquisadores abordam a semiótica pelo viés econômico propriamente dito, ele se direciona ao sentido da viagem e seu preço torna-se a consequência de seu valor cultural. Já Santillán (2011) buscou por significados em imagens fotográficas comerciais através de análises interpretativas e estudos iconográficos.

Apesar de o termo semiótica não ser mencionado na análise de Santillán (2011), seu estudo se aproxima da proposta de Mello (2019) ao trabalhar com a dimensão espaço-temporal na escala de planos, ângulos, enquadramentos, formatos, profundidade etc. Esse foi um breve resgate da aplicabilidade metodológica da semiótica do turismo em cenário internacional.

Desse modo, foi possível observar que, desde o final da década de 1980, a semiótica vem sendo utilizada na seara turística com propósitos comerciais. Mas, na proposta de Mello (2019), esse ferramental extrapola o âmbito comercial e se aproxima do comportamental e do experiencial acadêmico.

Primeiramente, gostaria de destacar a importância, para o campo turístico brasileiro, desse tipo de produção e da disseminação de novas estratégias metodológicas, pois se nota a intenção de ultrapassar os padrões clássicos e disciplinares na maneira de se produzir conhecimento.

Cientes da existência de pesquisadores que preferem permanecer nas metodologias tradicionais, precisamos ter em mente que o conhecimento se produz e reproduz em ciclos evolutivos. Assim, apesar da resistência em aceitar novas 
alternativas metodológicas, docentes e pesquisadores deveriam incentivar cada vez mais os jovens acadêmicos a trilharem semelhantes caminhos, ainda que em caráter experimental, com métodos propositivos, pois somente com a experimentação serão atendidas ou refutadas suas exigências e expectativas, e a semiótica do turismo se consolidaria enquanto metodologia no cenário brasileiro.

No cenário nacional, nota-se uma carência interpretativa na comunicação visual turística, dentro e fora da academia, como a disseminação de conteúdo visual, principalmente nas redes sociais. Nelas, são facilmente observados sujeitos que, por falta desse aprofundamento teórico em semiótica do turismo, produzem conteúdo, estudos ou peças publicitárias superficiais e/ou com ruídos na comunicação; sujeitos que recorrem à semiótica do turismo de forma antiética; e, em menor grau, sujeitos que, apesar da ética e rigor metodológico para utilizar a semiótica do turismo, possuem pouca visibilidade. Por isso, para gerar um efeito de blindagem tanto no enunciador (ético) quanto no enunciatário (leigo), há a necessidade de ações disruptivas ao se interpretar comunicações visuais turísticas através da semiótica do turismo aplicada.

A obra Semiótica do Turismo Aplicada, apesar de ter sido publicada em 2019, demonstra relevância e validade por apresentar abordagens alternativas e necessárias à seara das pesquisas visuais turísticas. Faz-se essa afirmativa como uma crítica perante o avistamento de um cenário brasileiro, em que as pesquisas encontram inúmeras barreiras desde o planejamento, a produção e a divulgação.

Em muitos casos essa limitação metodológica tradicional se reproduz em vários estudos, o que não está errado, porém demonstra que o nível metodológico se encontra estagnado. Assim, esse cenário é permeado por estudos e artigos que, apesar de apresentarem semelhante temática, ainda se reservam como ensaios iniciais, necessários ao avanço desse tipo de pesquisa, porém um tanto quanto rasos ou equivocados em alguns casos ou que empregam teorias e conceitos semióticos sem o rigor metodológico necessário.

Essa falta de rigor metodológico acarreta o uso equivocado das teorias e métodos e, com isso, observa-se, em alguns casos, discursos que se aproximam da falta de ética por parte dos enunciadores ao empregar subliminarmente métodos e técnicas semióticas atreladas a métodos e técnicas de marketing, com o propósito de iludir, persuadir ou induzir o turista.

Essas interferências ou ruídos, ora por influenciadores, ora pela publicidade, condicionam o turista a se transformar em um sujeito hedonista/narcisista que passa a reproduzir o discurso de que para ser feliz, é necessário o consumo exacerbado seguido pela divulgação visual como comprovação desse status de turista (Mello, 2019).

Visto que a teoria semiótica requer muito tempo de estudo para o completo domínio da área, das correntes de pensamento, modelos e aplicações distintas, a abordagem defendida por Mello (2019) figura como uma estratégia metodológica de semiótica especial, eficiente para a leitura e interpretação verbo-visual de imagens tidas como turísticas, com propositivas apresentadas na forma de um desenho específico, que aqui nomeio respeitosamente de Método Mello.

Para tanto, quem optar pelas visualidades no universo turístico, seja para pesquisar, trabalhar, ou produzir conteúdo para plataforma virtual, essa obra não deve ser a única fonte consultada para uma pesquisa em turismo visual, mas pode ser a primeira a direcionar os próximos passos. Sugere-se beber de outras fontes 
teóricas complementares, com o propósito de apreender nas entrelinhas o desejo do "outro", o que mostrar ou ocultar de maneira ética, o que merece ser ressaltado e, principalmente, qual a mensagem que se almeja transmitir ou, na via contrária, interpretar o que o enunciador quer dizer com esta ou aquela peça verbo-visual.

Dado que a leitura e a interpretação da obra são pessoais e um tanto quanto subjetivas, essa resenha trouxe como apresentação os principais tópicos abordados na obra como uma ação para que o leitor possa adentrar na temática e dar o primeiro passo em busca deste conhecimento.

Diante do exposto, considerando a originalidade e os benefícios acadêmicos como primeiro livro do gênero direcionado às pesquisas visuais turísticas no Brasil, a obra foi bem-organizada, as teorias foram bem fundamentadas, a abordagem demonstrou ser flexível e útil ao proporcionar de forma decodificada e sistematizada o elo entre a descrição teórica, a análise e a indução à prática.

Apesar dessa primeira edição não possuir versão digital, a obra física é de fácil aquisição através do site da editora por um valor simbólico. Portanto, recomenda-se a leitura integral do livro Semiótica do Turismo Aplicada para pesquisadores, estudantes de graduação e pós-graduação em Turismo e para leitores em geral como incentivo inicial às pesquisas no campo das visualidades turísticas.

\section{REFERÊNCIAS}

Culler, J. (1990). The semiotics of tourism. In J. Culler, Framing the sign: Criticism and its institutions (pp. 1-10). Norman, OK: University of Oklahoma Press.

Echtner, C. M. (1999). The semiotic paradigm: implications for tourism research. Tourism Management, 20(1), 47-57. https://doi.org/10.1016/S0261-5177(98)00105-8

Greimas, A. J. (1973). Semântica estrutural. São Paulo, SP: Cultrix.

Jaworski, A., \& Thurlow, C. (2010). Semiotic landscapes: Language, image, space. London, UK: Continuum.

Jurado, A. C. (2002). El estudio de los objetos y la semiótica. Cuicuilco, 9(25), 1-19.

Lotman, Y. M., \& Ouspensky, B. A. (1976). Travaux sur les systèmes de signes. Paris, FR: Complexe.

Mello, C. (2019). Semiótica do turismo aplicada. Curitiba, PR: Appris.

Peirce, C. S. (1997). Semiótica. São Paulo, SP: Perspectiva.

Rickly-Boyd, J. M. (2009). The tourist narrative. Tourist Studies, 9(3), 259-280. https:// doi.org/10.1177/1468797610382701

Santillán, V. L. (2011). Fotografía, turismo y consumo. Bases conceptuales para el análisis de la imagen fotográfica comercial turística Reflexión Académica en Diseño y Comunicación №XVI, 12(16), pp. 140-144.

Urbain, J.-D. (1989). The tourist adventure and his images. Annals of Tourism Research, 16(1), 106-118. https://doi.org/10.1016/0160-7383(89)90033-9

Recebido em: 06/07/2021

Aprovado em: 25/08/2021 